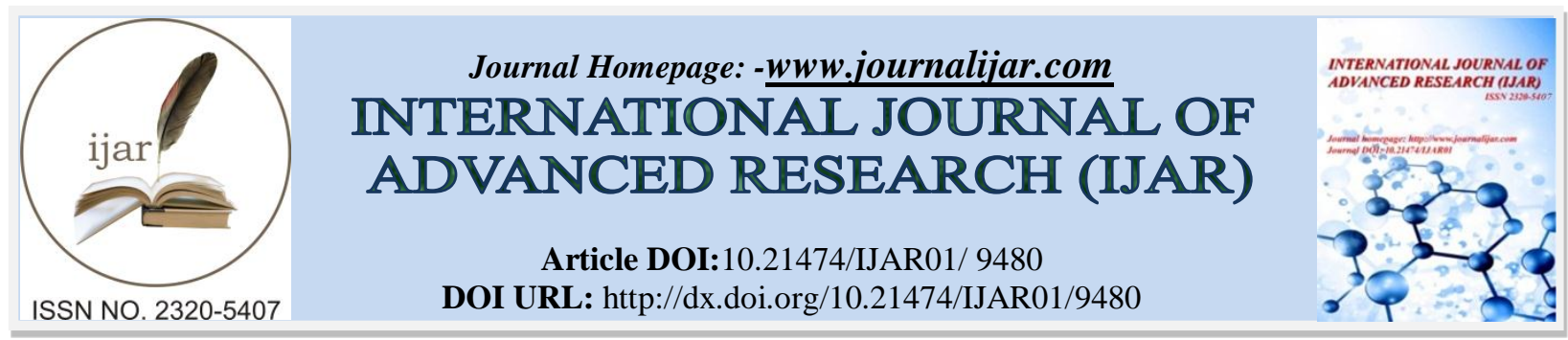

RESEARCH ARTICLE

\title{
EFFECT OF ABDOMINAL MASSAGE ON UTERINE INVOLUTION AMONG POSTNATAL MOTHERS- A PILOT STUDY.
}

\author{
Ms. Sandhyakumari Rajbhar ${ }^{1}$ and Ms. Anjali Tiwari ${ }^{2}$.
}

1. M.Sc Nursing, Manikaka Topawala Institute of Nursing, CHARUSAT, Gujarat.

2. Assistant Professor and HOD, Dept. Of Obstetrics \& Gynaecological Nursing, ManikakaTopawala Institute of Nursing, CHARUSAT, Gujarat.

\section{Manuscript Info}

\section{Manuscript History}

Received: 03 June 2019

Final Accepted: 05 July 2019

Published: August 2019

Key words:-

Evaluate Effect, Abdominal Massage,

Uterus Involution, and Postnatal Mother.

\begin{abstract}
Introduction and Background: Postnatal period which was considered as a crucial phase to determine the survival rate of mother, baby and health of both. Common postnatal complication is post partum haemorrhage due to various causes such as retained placenta, genital tract injury or may be due to no involution of uterus, infection, obstructed labour process and etc. This study was conducted to evaluate the effect of abdominal massage on uterine involution among postnatal mother.

Methodology: Quantitative approach, quasi experimental and pre-test post-test control group design was used in this study. The study was conducted in selected hospital of Central Gujarat Region and sample was selected by convenient sampling technique, 5 samples in each group. Collection of data is done by using demographic tool and measuring fundal height. The experimental received intervention twice a day for three consecutive day with routine care whereas in control group only routine care was given.

Result: Descriptive and inferential statistics was done to analyse the data. The result showed that there was reduction in mean score of uterus involution from before (15.31) to after (12.00) implementation of abdominal massage twice a day for 3 consecutive days in experimental group and $p$ value is 0.043 . In the control group the mean score of uterus involution reduce from 15.62 to 13.06.

Conclusion: Hence, the conclusion of the study was that there is significant effect of abdominal massage on uterus involution rate among postnatal mothers to enhance the rate of uterus involution.
\end{abstract}

Copy Right, IJAR, 2019,. All rights reserved.

\section{Introduction:-}

Pregnancy period in every women life is great experience and unforgotten moment to which every woman wants to enjoy and feel great. During the pregnancy period a women only required a good family support as well as good medical facility to for care of her future child and herself. ${ }^{[1]}$ Throughout pregnancy the mothers or women come across various life threatening complication and risk factors. The mother's problem or struggle not going to finish after delivery of child, there was chance of occurrence of different life threatening complication which will affect mother physically, psychologically and emotionally ${ }^{[2] .}$ 
Just after delivery of placenta to six week after delivery is known as puerperium period or postnatal period which was considered as a crucial phase to determine the survival rate of mother, baby and health of both. ${ }^{[3]}$

According to the World Health Report of 2003 the common postnatal complication are post partum haemorrhage which may be due to the retained placenta, subinvolution, infection, and obstructed labour process and all this complication are leading causes of the maternal morbidity

The term uterine involution refers the process in which uterus and other reproductive organs revert back to its normal as pre-pregnant state and size after delivery. If uterine involution not take place, it lead to subinvolution of uterus which is considered as leading cause of delayed postpartum haemorrhage which may cause by pathological reason like retained placenta. ${ }^{[4]}$

According to the WHO approximately 5 mothers died in India every hour due to occurrence complication during pregnancy, at time of delivery and after delivery. According to Global Health Body (GHB) approximately 45 thousands women died yearly in India and cause was related to childbirth process which accounts for $17 \%$ of deaths globally.

Abdominal massage or fundal massage or uterine massage is a procedure used to prevent the post partum haemorrhage just after delivery to make uterus contract well or to increase tonicity. Abdominal massage during postnatal period helps to decrease blood loss and uterine cramps. Routine massage of uterus with other routine care can prevent subinvolution, primary and postpartum haemorrhage ${ }^{[5]}$.

\section{Material And Methods:-}

The research approach used in this study was Quantitative approach. Quasi experimental, pre-test post-test control group design was used. The study was conducted in selected hospital of Central Gujarat Region. 10 samples were selected by using convenient non-probability sampling technique, 5 in experimental and 5 in control group were selected. The tools used to gathering data were demographic variables and fundal height measurement by using the measure tape. The experimental group received intervention twice a day for 3 consecutive with routine care whereas in control group only fundal height measurement with routine care.

\section{Result:-}

Analysis of data is done by the use of descriptive and inferential statistics. The result of study showed that there was reduction in mean score of uterus involution from before (15.31) to after (12.00) implementation of abdominal massage twice a day for 3 consecutive days in experimental group. In the control group the mean score of uterus involution reduce from 15.62 to 13.06

Table 1:-Finding related to comparison of mean score of uterus involution between $1^{\text {st }}$ day before intervention and $3^{\text {rd }}$ after intervention in experimental group.

\begin{tabular}{|c|c|c|c|c|c|}
\hline \multicolumn{7}{|c|}{ Paired Samples Statistics For Experimental Group } \\
\hline \multicolumn{2}{|c|}{} & Mean & Std. Deviation & Wilcoxon Test & P Value \\
\hline \multirow{2}{*}{ Pair 1 } & Day 1 Before Intervention & 15.31 & 2.38 & 2.05 & 0.043 \\
\cline { 2 - 4 } & Day 3 After Intervention & 12.00 & 1.71 & & \\
\hline
\end{tabular}

Table 1 showed that there was significant decline in mean score after intervention, on $1^{\text {st }}$ day before intervention mean score was 15.31 which decline to mean score 12.00 by $3^{\text {rd }}$ day after intervention and $p$ value was 0.043 .

Table 2:-Finding related to comparison of mean score between control and experimental group for uterus involution rate on $1^{\text {st }}$ and $3^{\text {rd }}$ day.

\begin{tabular}{|l|l|r|r|}
\hline \multicolumn{2}{|c|}{ Group } & N & Mean Score \\
\hline \multirow{2}{*}{ Day 1 Before Intervention } & Control & 5 & 15.62 \\
\cline { 2 - 4 } & Experimental & 5 & 15.31 \\
\hline \multirow{2}{*}{ Day3 Before Intervention } & Control & 5 & 13.06 \\
\cline { 2 - 4 } & Experimental & 5 & 12.02 \\
\hline
\end{tabular}

Table 2 showed that mean score difference is significantly high in experimental group was 3.29 in comparison to control group which has mean score difference 2.56. 
Graph 1:-comparison of mean score between control and experimental group on $1^{\text {st }}$ day before intervention and day $3^{\text {rd }}$ before intervention.

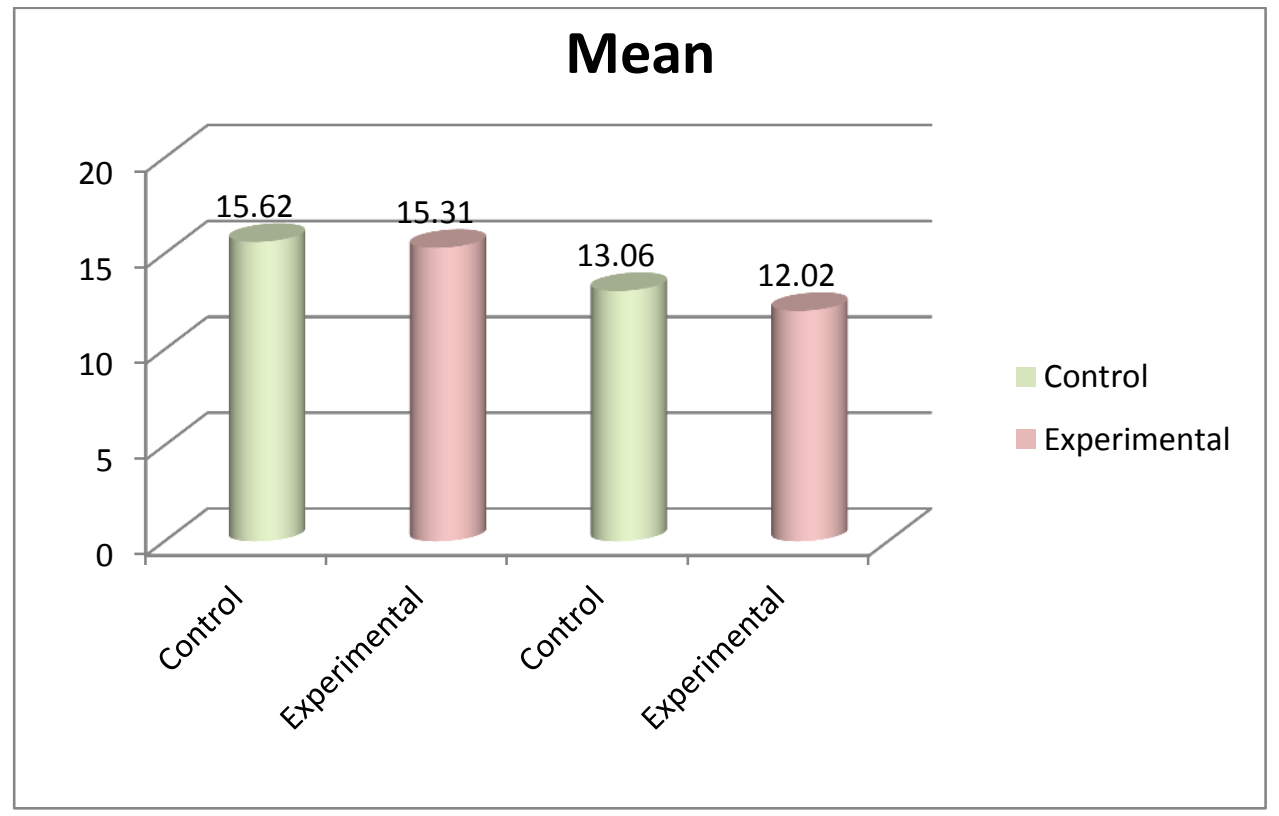

Graph 1 showed that the comparison of uterus involution rate between experimental and control group on $1^{\text {st }}$ day before intervention and $3^{\text {rd }}$ day before intervention which showed that significant reduction in uterus involution rate among experimental group in comparison to control group.

\section{Conclusion:-}

The study was conducted on 10 postnatal mothers ( 5 in experimental \& 5 in control group). The mothers get abdominal massage for 3 consecutive days which is easy to implement without any resource and helpful to increase the rate of uterus involution. So, similar study can be performing on large numbers of sample to make it generalized and to determine the effect of abdominal massage on uterus involution. The postnatal mother and also others people can use this measure for uterus involution as well as to reduce complication due to uterus subinvolution like secondary postpartum haemorrhage and etc.

\section{References:-}

1. Jessica evert. Introduction to pregnancy. Mentalhelp.net. 2019 [cited 2019 april 7]. Available from: https://www.mentalhelp.net/articles/introduction-to-pregnancy

2. 20 common postnatal complications \& their solutions [internet]. Firstcry parenting. 2018 [cited 2019apr7]. Available from: https://parenting.firstcry.com/articles/20-postpartum-complications-you-may-experience/

3. Akibu, mohammed, tsegaye, tewodros, sodere. Prevalence and determinants of complete postnatal care service utilization in northern shoa, ethiopia [internet]. Journal of pregnancy. Hindawi; 2018 [cited 2019apr7]. Available from: https://www.hindawi.com/journals/jp/2018/8625437/

4. Keyword analysis \& research: subinvolution of placenta [internet]. Traffic analysis. [Cited 2019apr7]. Available from: http://www.sitedownrightnow.com/search/subinvolution-of-placenta

5. Doula [internet]. Wikipedia. Wikimedia foundation; 2019 [cited 2019apr7]. Available from: https://en.wikipedia.org/wiki/doula. 